\title{
Relationships between molar mass and fracture properties of segmented urethane and amide copolymers modified by chemical degradation
}

\author{
Bardin Antoine 1, 2, 3, Le Gac Pierre Yves ${ }^{1}$, Bindi Hervé 2, Fayolle Bruno 3, *
}

${ }^{1}$ Marine Structure Laboratory IFREMER, Centre de Bretagne Plouzané ,France

2 Thales DMS France Valbonne, France

3 PIMM laboratory, Arts et Metiers Institute of Technology CNRS, Cnam, HESAM Université

Paris ,France

* Corresponding author : Bruno Fayolle, email address : bruno.fayolle@ensam.eu

\begin{abstract}
:
This publication highlights the structure-property relationships in several thermoplastic elastomers (TPEs): one poly(ether-block-amide) and two thermoplastic polyurethane elastomers with ester and ether soft blocks. Structural changes are induced by chemical degradation from virgin samples through hydrolysis and oxidation. Molar mass measurements show an exclusive chain scission mechanism for all TPEs, regardless of the chemical modification condition. Mechanical behavior was nevertheless obtained from uniaxial tensile testing and fracture testing while considering the essential work of fracture (EWF) concept. During the macromolecular scission process, elongation at break shows a plateau followed by a drop, while stress at break decreases steadily. Once again, the trend is identical for all TPEs in all conditions considered. The $\beta w p$ parameter determined using the EWF concept exhibits an interesting sensitivity to scissions (i.e., molar mas decrease). Plotting elongation at break as a function of molar mass reveals a strong correlation between these two parameters. This master curve is particularly remarkable considering the range of TPEs and chemical breakdown pathways considered (hydrolysis and oxidation at several temperatures). Relevant structure-property relationships are proposed, highlighting that molar mass is a predominant parameter for determining the mechanical properties of thermoplastic elastomers.
\end{abstract}

Keywords : essential work of fracture, poly(ether-block-amide), structure-property relationship, thermoplastic elastomer, thermoplastic polyurethane elastomer 
Thermoplastic elastomers (TPEs) have attracted growing interest since their emergence in the 1970s. Among others, this attention may be explained by the fact that these materials present a thermoplastic chemical structure while exhibiting elastomeric properties. Here we investigate the relationship between molar mass and fracture properties of TPEs using specific chemical degradation mechanisms. This method allows us to change the molecular structure by inducing molar mass changes, while other structural properties remain unaffected. Segmented urethane and amide copolymers present a complex multiphase morphology composed of a hard phase, soft phase, and interphase. Interchain physical bonds in the form of $\mathrm{H}$-bonding or crystallinity formed between highly polar groups that make up the hard blocks lead to the formation of a 3D network. This feature is referred to as physical crosslinking in contrast to chemical crosslinking, which occurs in thermoset elastomers. Furthermore, soft and hard phases naturally segregate due to their thermodynamic incompatibility, resulting in discrete nano or micro-hard phases, whereas macromolecules interconnect, being dispersed in a soft phase matrix. ${ }^{1,2}$

Many parameters can be adjusted to obtain specific properties of segmented urethane and amide copolymers. The chemical structure of hard and soft blocks obviously play a major role. For instance, thermoplastic polyurethane elastomers (TPUs) with polyester soft blocks lead to lower phase separation than TPUs with polyethers., ${ }^{3,4}$ Diisocyanate aromaticity and symmetry also affect properties. Hard phase properties in turn depend on molecular packing governed by crystallinity and $\mathrm{H}$-bonding density. ${ }^{5,6}$ Elastomeric properties are reported for a high soft block content, typically between 60 and $85 \%$ w. ${ }^{7,8}$ As a result, the hard block/soft block ratio as well as the size of the respective blocks are also a major parameter governing properties. For instance, increasing the hard block content leads to higher $\mathrm{H}$-bonding and crystallinity, ${ }^{9}$ thus inducing higher phase separation. Globally, increasing the hard block content causes the elastic modulus and stress at break to increase, while it causes elongation at break to decrease. ${ }^{10-12}$ For a given hard/soft block molar ratio, increasing the soft block molecular mass leads to an increase in elongation at break and a decrease in modulus. ${ }^{13}$ For TPUs, the chain extender nature is also reported to affect mechanical properties. In particular, chain extenders with an even number of $-\mathrm{CH}_{2}$ - groups adopt a fully extended conformation, which promotes $\mathrm{H}$-bonding and higher crystallinity order. ${ }^{13}$

The overall TPE mechanical properties heavily depend on the relative amount of soft and hard phases as well as the intrinsic properties of each phase. The molar mass of the soft segment has a significant influence on mechanical properties, especially for TPEs having low hard segment content. It has been proposed that if the soft segment molar mass is higher than the molar mass between entanglements $\left(\mathrm{Me}_{\mathrm{e}}\right)$, entanglements improve elongation at break ${ }^{14}$. Ertem et al. ${ }^{15}$ studied polyurethaneuras based on poly(propylene oxide)glycol (PPG) segments with a molar mass between 2 and $12 \mathrm{~kg}^{\mathrm{mol}}{ }^{-1}$. They showed that the tensile strength decreases with molar mass, which was expected by the authors since the molecular weight of PPG increases the interdomain spacing, but also leads to decrease the hard segment content. It is noteworthy that in these studies, soft segment molar mass is modified through synthesis, which also leads to modify the interdomain spacing. It is then challenging to determine the respective contributions of soft segment molar mass and interdomain spacing on mechanical properties. In our study, we expect to modify soft segment molar mass without inducing interdomain spacing change, using chemical degradation. 
Molar mass changes were induced by using selective chemical degradation mechanisms such as oxidation and hydrolysis. Given that oxygen or water molecules only diffuse in the soft phase, the chemical degradation will lead to a chain scission process, which will modify the global molar mass. The consequences of chain scissions on mechanical properties are also assessed. To identify relevant relationships between molar mass and fracture properties, we use three types of segmented copolymers:

- $\quad$ a polyether-based TPU, mainly sensitive to oxidation, which causes a molar mass decrease ${ }^{16}$ It can also undergo hydrolysis in specific environments or with longterm ageing.

- $\quad$ a polyester-based TPU, for which chain scissions can be induced by hydrolysis or oxidation. Both mechanisms are considered to be random along the soft blocks.

- $\quad$ a poly(ether-block-amide) (PEBA), for which oxidation induces chain scissions considered to be random, while hydrolysis impacts only the ester group linking the hard polyamide block and soft polyether block (see FIGURE 1).

Different approaches are available when considering molar mass-failure property relationships depending on the polymer family. Segmented urethane and amide copolymers are commonly categorized between conventional thermoplastic polymers and thermoset elastomers. Considering that both families have been extensively studied and that their behavior is now well known, is it possible to use the existing laws from one or the other family to describe segmented copolymers behavior? Or do these TPEs tend to represent a specific new polymer group with its own characteristics?

For instance, it is well known that in conventional linear thermoplastic polymers, the chain scission process is responsible for embrittlement, highlighted by a drop in failure properties when molar mass decreases below a critical value. This critical molar mass $\mathrm{M}_{\mathrm{c}}{ }_{\mathrm{c}}$ is related to the molar mass between entanglements $M_{e}$ as $M_{c}^{\prime}=4-5 M_{e}$. In the case of semi-crystalline polymers, the existence of such a critical molar mass is more questionable, since the crystalline phase affects the deformation mechanisms associated with the fracture process. However, a similar behavior was observed. ${ }^{17} \mathrm{~A}$ shared trend linking $\mathrm{M}_{\mathrm{c}}{ }_{\mathrm{c}}$ and $\mathrm{M}_{\mathrm{e}}$ was highlighted for several semi-crystalline polymers such as PP, PE, PTFE, and POM according to $\mathrm{M}^{\prime}{ }_{\mathrm{c}}=50 \mathrm{Me}$.

Nevertheless, the behavior of elastomers is also unclear. It is commonly considered that elongation at break $\left(\lambda_{b}\right)$ is related to the crosslinking density ( $v$ through a power law, as $\left.\lambda_{b} \propto v^{n}\right)$. Kuhn first theorized this approach in 1946 with an exponent $n$ equal to $-0.5 .{ }^{18}$ This relationship was verified in some specific cases such as gamma-irradiated EPDM, ${ }^{19}$ with an increasing elongation at break induced by a predominant scission process. Natural rubber also seems to exhibit a correlation between $\lambda_{b}$ and $v$, although an empirical $n$ closer to -0.75 was reported. ${ }^{20,21}$ However, this law cannot be applied to describe the embrittlement observed during a chain scission process, since the crosslink density decrease caused by scissions ${ }^{19}$ would result in a $\lambda_{b}$ increase. Overall, even if some influencing parameters have been highlighted, the global and relevant structure-property relationships in elastomers have not yet been completely elucidated, which is even more valid for TPEs.

In this context, selective chemical degradation is an interesting tool, as it allows us to study a variety of networks produced from virgin material and from which potential correlations can 
be highlighted. Hydrolytic and oxidative degradations were considered here, enabling to produce samples with various molar masses through a molecular chain scission mechanism. Though such temperatures were not used in ours case, it is noteworthy that scissions have been observed in a polyurethane elastomer exposed to temperatures above $180^{\circ} \mathrm{C}$, which also led to the reverse reaction (urethane formation) ${ }^{22}$.

The microstructural changes induced by the hydrolytic and oxidative degradation processes are characterized through molar mass measurements that give direct information about the chain scission mechanisms. Along with assessing any structural changes, the mechanical property changes are also characterized. Relationships between mechanical failure properties and molar mass are then investigated based on extensive sets of data collected for two TPUs and one PEBA aged in seawater and air at several temperatures. 


\section{EXPERIMENTAL}

\subsection{Materials}

Two TPU grades, commercialized as Desmopan ${ }^{\circledR} 2586$, and 9370, were supplied by Covestro. Both grades are constituted of 4,4'-methylene diphenyl diisocyanate (MDI) and butylene glycol (BDO) as hard blocks. Desmopan 2586 is constituted of poly(1,4-butylene adipate) (PBA) as polyester soft blocks. Grade 9370 is comprised of poly(tetramethylene oxide) (PTMO) as polyether soft blocks. Grade Pebax ${ }^{\oplus} 2533$, constituted of polyamide 12 (PA12) hard blocks and poly(tetramethylene oxide) (PTMO) soft blocks, was purchased at Arkema. FIGURE 1 presents the chemical structures of the three grades, and

TABLE 1 summarizes their main properties. Hard block weight fraction $W_{\text {hard }}$ was determined with H-NMR, except for PEBA that was averaged from the literature. ${ }^{10,23,24}$ Hardness values were taken from the technical data sheet, density was calculated from the weight difference in air and water, and number average molar mass $M_{n}$ was measured using gel permeation chromatography (GPC).

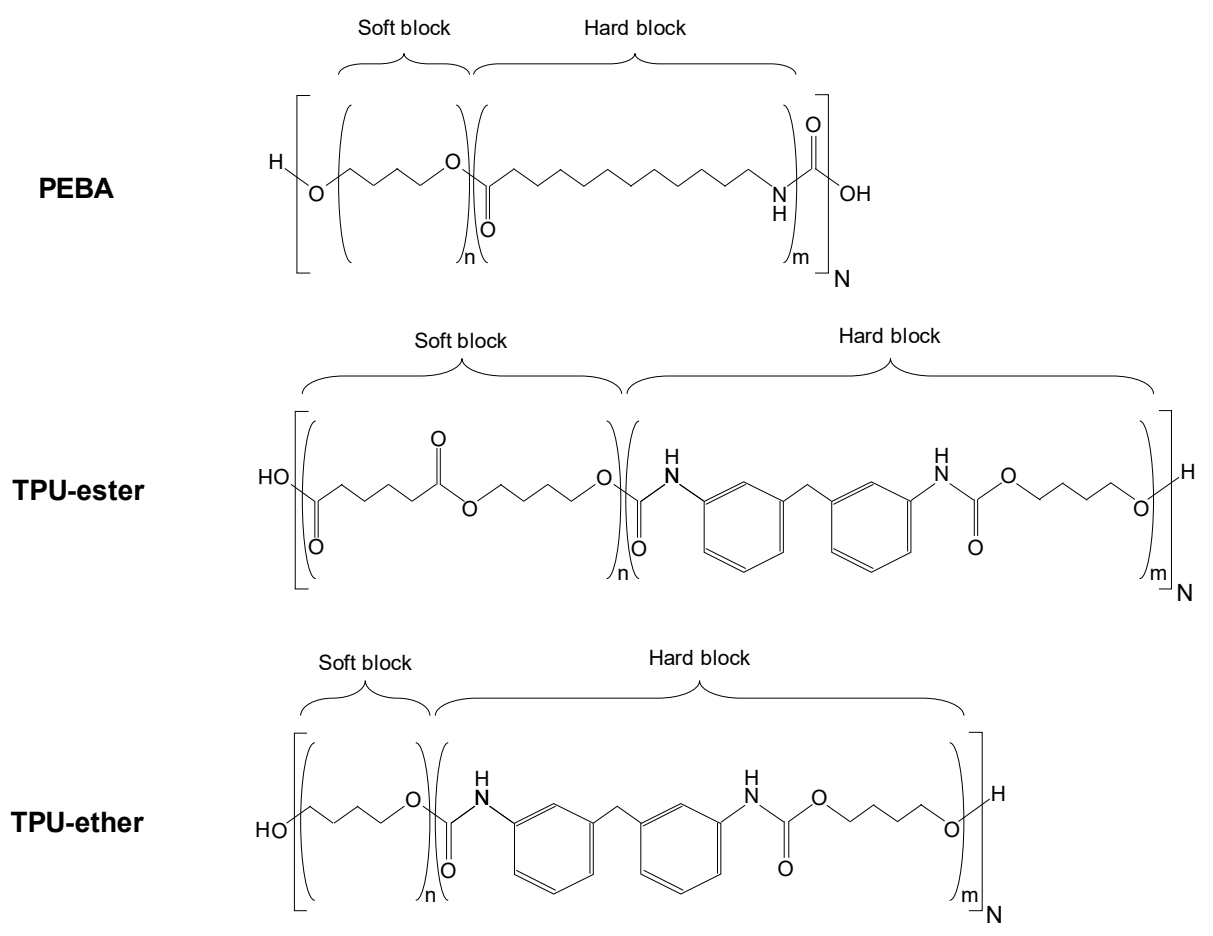

FIGURE 1 Chemical structure of thermoplastic elastomers.

\begin{tabular}{|c|c|c|c|c|c|c|c|}
\hline Grade & $\begin{array}{l}\text { Commercial } \\
\text { reference }\end{array}$ & Hard block & Soft block & $\mathbf{W}_{\text {hard }}$ & $\begin{array}{l}\text { Hardness } \\
\text { (Shore A) }\end{array}$ & $\begin{array}{l}\text { Density } \\
\left(\text { g.cm }{ }^{-3}\right)\end{array}$ & $\begin{array}{l}\mathrm{M}_{\mathrm{n}} \\
\left(\mathrm{kg} \cdot \mathrm{mol}^{-1}\right)\end{array}$ \\
\hline PEBA & $\operatorname{Pebax}^{\circ} 2533$ & PA12 & PTMO & $0.24^{a}$ & 77 & 1.01 & 59.0 \\
\hline TPU-ester & Desmopan 2586 & $\mathrm{MDI}+\mathrm{BDO}$ & PBA & 0.36 & 86 & 1.19 & 68.7 \\
\hline TPU-ether & Desmopan 9370 & $\mathrm{MDI}+\mathrm{BDO}$ & PTMO & 0.17 & 70 & 1.06 & 40.9 \\
\hline
\end{tabular}


TABLE 1 Main properties of thermoplastic elastomers.

Raw materials were supplied in granular form. Granules were dried at $80^{\circ} \mathrm{C}$ for $15 \mathrm{~h}$ before processing. Plates were injected on a DK CODIM 175/410 injection molding machine according to supplier specifications to obtain $2.5 \mathrm{~mm}$-thick PEBA plates and $1.5 \mathrm{~mm}$-thick TPU plates. The choice of low-thickness plates took into account the chemical degradation properties in order to ensure that oxidative and hydrolytic processes were not controlled by air or water diffusion and that the degradation was uniform across thickness.

\subsection{Chemical degradation conditions}

Plates were annealed at $110^{\circ} \mathrm{C}$ for $15 \mathrm{~h}$, under vacuum to thermally stabilize their microstructure before chemical degradation. Cooling was performed by turning off the oven and letting the temperature slowly decrease to ambient. Differential scanning calorimetry analysis (not shown here) confirmed a stable microstructure (no melting peak) up to $110^{\circ} \mathrm{C}$.

For seawater exposure, samples were immersed in tanks filled with continuously renewed natural seawater at five temperatures: $25,40,60,80$, and $90 \pm 2{ }^{\circ} \mathrm{C}$. They were removed from the tanks after a definite ageing time and carefully wiped with a paper towel. To avoid further degradation, samples were fully dried in a desiccator filled with silica gel (i.e., $\mathrm{RH}$ equal to 0 ) at $40{ }^{\circ} \mathrm{C}$ for $48 \mathrm{~h}$. Air exposures were performed in Memmert ovens with forced convection at temperatures ranging from 80 to $110 \pm 2{ }^{\circ} \mathrm{C}$.

\subsection{Molar mass measurements}

Two GPC set-ups were used, with a different eluent required for PEBA and TPUs. PEBA analyses were performed by the PeakExpert Company. Analyses were performed at $20^{\circ} \mathrm{C}$ using a mixture of hexafluoroisopropanol and $0.1 \mathrm{M}$ potassium trifluoroacetate as eluent. An apparatus was equipped with a pre-column and two columns packed with $7 \mu \mathrm{m}$ PFG particles of $1000 \AA$ and $100 \AA$ pore size, respectively. The detection was performed using a Waters 2414 differential refractive index detector. The calibration was performed with poly(methyl methacrylate) samples. For TPUs, analyses were performed at $40{ }^{\circ} \mathrm{C}$ using tetrahydrofuran as eluent on a Malvern Viscotek TDA apparatus equipped with two Malvern T3000 and T6000 columns with a Malvern refractive index detector at an elution rate of $1 \mathrm{~mL} / \mathrm{min}$. Polystyrene samples were used for calibration. Number average molar mass $M_{n}$ and mass average molar mass $M_{w}$ were calculated as relative values to the corresponding calibration.

\subsection{Mechanical tests}

Uniaxial tensile tests were performed at a rate of $50 \mathrm{~mm} / \mathrm{min}$ on a $10 \mathrm{kN}$ Instron machine in a room regulated at $21 \pm 1{ }^{\circ} \mathrm{C}$ and $50 \%$ relative humidity. A $500 \mathrm{~N}$ cell was used to measure load. ISO 37:2005 type 3 dogbone tensile sample was used with duct tape marks placed at the gauge length ends. Strain was measured using an optical extensometer. Photographs of sample deformation were taken at a rate of one image per second. Specific software developed at IFREMER was then used to track the relative displacement of the two duct tape marks to calculate the elongation. The duct tape marks were initially placed $15 \mathrm{~mm}$ apart on the gauge length.

The tensile machine used for the standard uniaxial tensile test was also used to perform the essential work of fracture (EWF) tests. EWF tests were conducted on deeply double-edge- 
notched tensile (DENT) specimens. Samples were manually notched with a cutter to obtain the desired ligament length I according to the ESIS protocol, ${ }^{25}$ which was then accurately measured with an optical microscope.

Elongation and displacement were measured with an optical extensometer. EWF tests were performed at a rate of $50 \mathrm{~mm} / \mathrm{min}$. The total work of fracture $\left(W_{f}\right)$ was experimentally determined as the area below the load-displacement curve. The specific total work of fracture $\left(w_{f}\right)$ was calculated as $W_{f}$ divided by the sample initial section.

\subsection{Small and Wide X-Ray Scattering (SAXS and WAXS)}

SAXS and WAXS analysis were performed on the high brilliance SWING beamline at the Soleil Synchrotron facility. The monochromator was set at $12 \mathrm{KeV}$. Patterns were recorded at room temperature, with a CCD detector at $6 \mathrm{~m}$ from the sample for SAXS, and $0.5 \mathrm{~m}$ for WAXS. 1D curves were obtained by circular averaging of 2D images, using the Foxtrot software. 10 images were taken for each sample, from which final 1D curve is averaged. Fityk software was used for diffractogramme deconvolution. 


\subsection{Macromolecular change}

Depending on the material and exposure condition considered, hydrolysis and oxidation are known to affect polymer structure through two main events: scission and crosslinking. The molar mass of linear polymer is greatly affected by these events, which makes it a relevant property for assessing ageing. Unlike thermoset elastomers, it is possible to solubilize the thermoplastic elastomers studied here into suitable solvents, and consequently, measure their molar mass with GPC. Ageing campaigns of the three TPEs (PEBA, TPU-ester, and TPUether) were performed in seawater tanks at $25,40,60,80$, and $90^{\circ} \mathrm{C}$, and in ovens at 80,100 , and $110^{\circ} \mathrm{C}$.

First, we consider molar mass changes for all TPEs immersed in seawater at a given temperature (FIGURE 2). A $M_{n}$ decrease is observed for all grades, although the kinetics strongly depends on the chemical nature. TPU-ester shows the fastest degradation, TPU-ether is the most resistant, and PEBA has an intermediate behavior. In a previous study, ${ }^{26}$ we clearly identified that the scission phenomenon (causing the molar mass decrease) observed for TPUester was due to hydrolysis. Here we assume that the same phenomenon occurs in PEBA and TPU-ether.

While the molar mass decrease observed for all segmented amide and urethane copolymers suggests a predominant scission mechanism, it is also possible that some crosslinking occurs, even though minor. For example, crosslinking occurs in polychloroprene rubbers immerged in seawater. ${ }^{27}$ Calculating the respective amount of scission and crosslinking with Saito's law confirmed that no crosslinking occurs in any of the TPEs during immersion. GPC chromatograms (not shown) show a molar mass distribution shift during ageing, while remaining unimodal, for all grades. The Dispersity $€$ remains around 2 (not shown). These are evidences of a random scission mechanism, as reported in the literature in numerous cases: PP under oxidation ${ }^{17}$, polyethylene under oxidation ${ }^{28}$, polyamides under oxidation ${ }^{29}$ and hydrolysis ${ }^{30}$ or PLA under oxidation ${ }^{31}$. Random scission is thus the exclusive mechanism taking place.

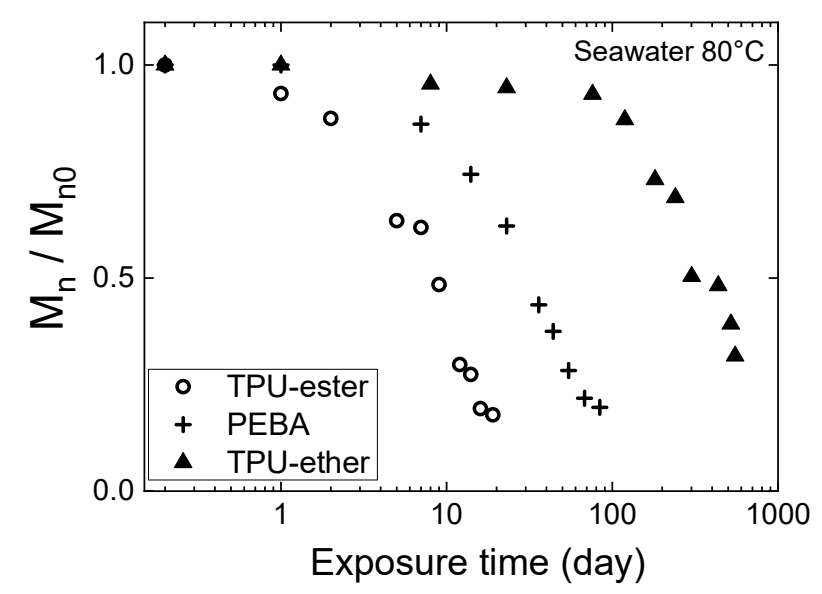

FIGURE 2 Molar mass decrease exhibited by TPEs when immersed in seawater at $80^{\circ} \mathrm{C}$. 
The difference in kinetics between segmented copolymers observed in FIGURE 2 is associated with the intrinsic capacity of the constituent functional groups in each polymer to hydrolyze (see FIGURE 1). The concentration of these hydrolysable groups is also a decisive parameter. Regarding group sensitivity, studies have shown that urethane hydrolysis is one to two orders of magnitude slower than that of amide and ester. ${ }^{32,33}$ Nuclear magnetic resonance analysis on TPU-ester, presented in Bardin et al., ${ }^{26}$ confirmed this observation. These tests confirmed that only the ester groups undergo hydrolysis, while urethane groups remain unaffected on the time range needed to reach the total loss of mechanical properties. Thus, urethane hydrolysis can be neglected in the TPU-ester case. As for PEBA, ester and amide hydrolysis rates are reported to be of the same order of magnitude. To identify its preferential hydrolysis site, PA12 homopolymer comprised of PEBA hard blocks was acquired and aged. By comparing the kinetics of PA12 and PEBA molar mass decrease, we highlighted that amide hydrolysis in PEBA is significantly slower. Hence, the ester group is the preferential site of scission for PEBA. The faster molar mass decrease observed for TPU-ester compared to PEBA can be explained by the higher ester content in the former $\left(7.14 \mathrm{vs} 0.79 \mathrm{~mol}^{-\mathrm{L}^{-1}}\right)$. Water-induced degradation of TPU-ether was reported to be caused by urethane hydrolysis, ${ }^{34}$ as the ether group is very resistant and only hydrolyzes under special forcing conditions. As previously said, urethane hydrolysis is significantly slower than ester hydrolysis, which explains the higher resistance exhibited by the TPU-ether. The hard segment functional groups, located in hard phases (aggregates of hard segments resulting from phase separation and linked through $\mathrm{H}$-bonding and possibly crystallinity) are less accessible to water, due to the already existing $\mathrm{H}$-bonds in this phase. Moreover, in the case of TPUs, the phenyl group next to the urethane hinders water accessibility. On the other hand, hard segments not aggregated but dissolved in the soft phase are accessible and may hydrolyse.

Exposure to air leads to molar mass decrease for all segmented urethane and amide copolymers (FIGURE 3). Identically to immersion ageing, a predominant scission mechanism was confirmed with Saito's law.

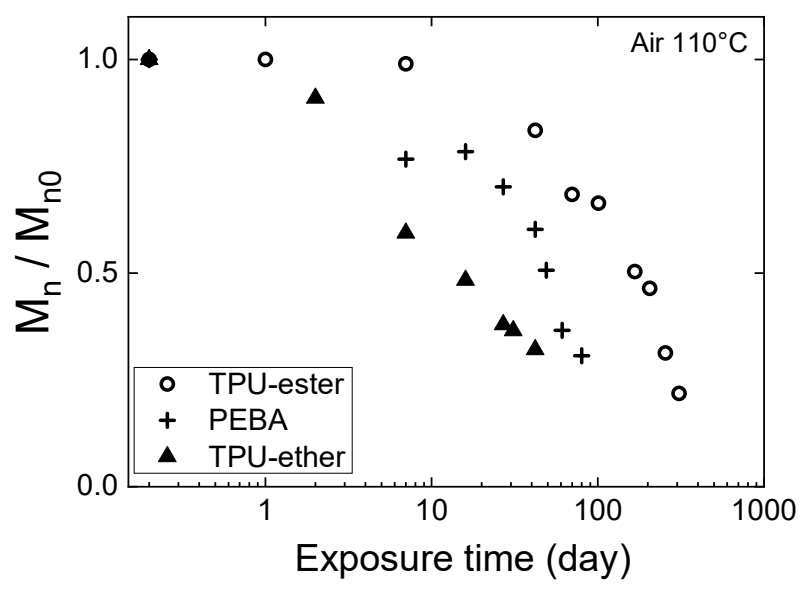

FIGURE 3 Molar mass decrease exhibited by TPEs when exposed to air at $110^{\circ} \mathrm{C}$.

It is interesting to observe that the kinetics are reversed compared to immersion: TPU-ether exhibits the fastest degradation, while TPU-ester is the most resistant; PEBA again has an intermediate behavior. TPU-ether and PEBA are composed of the same soft block, 
poly(tetramethylene oxide) (PTMO). The ether group, known to easily oxidize, is thus the preferential site of scission for both grades. This accounts for the faster decline compared to TPU-ester. The higher soft block content in TPU-ether ( $83 \%$ ) than in PEBA (76\%w) leads to a faster decrease for the former. Regarding TPU-ester, the identification of the oxidation site is not clear. Gardette et al. ${ }^{35}$ report that the ester group presents a higher resistance to oxidation than urethane. However, functional groups located in hard phases are less sensitive to oxidation due to the hindrance of oxygen diffusion by $\mathrm{H}$-bonds and crystallinity. ${ }^{36,37}$ FTIR analyses were performed to gain insight into the degradation process. No significant evidence of urethane or ester consumption through ageing was found, which was presumably due to the low sensitivity of the technique to detect the small concentration changes. We also investigated the possibility for TPU-ester to hydrolyze in ovens, as ageing campaigns were performed in humid ambient air. However, we observed that in the case of immersion at $80^{\circ} \mathrm{C}$, total degradation occurs after 10 days, but after 300 days when exposed to air at $110^{\circ} \mathrm{C}$. We thus assumed that water had very little effect on TPU-ester aged in air.

Overall, we highlighted that the three TPEs considered here (PEBA, TPU-ester, and TPU-ether) exhibit a molar mass decrease when immersed in seawater or exposed to air. The corresponding hydrolysis and oxidative processes induce an exclusive scission mechanism in all conditions considered here. For both seawater and air, molar mass decreases are temperature-accelerated, leading to highly different kinetics. The effect of temperature is shown in FIGURE 4 for PEBA immersed in seawater and TPU-ether in air. Temperature influence on TPU-ester hydrolysis can be found in Bardin et al. ${ }^{26}$ In conclusion, this molar mass decline is observed for all polymers in all exposure conditions. However, the kinetics are greatly affected by the TPE chemical structure as well as the nature and temperature of exposure.
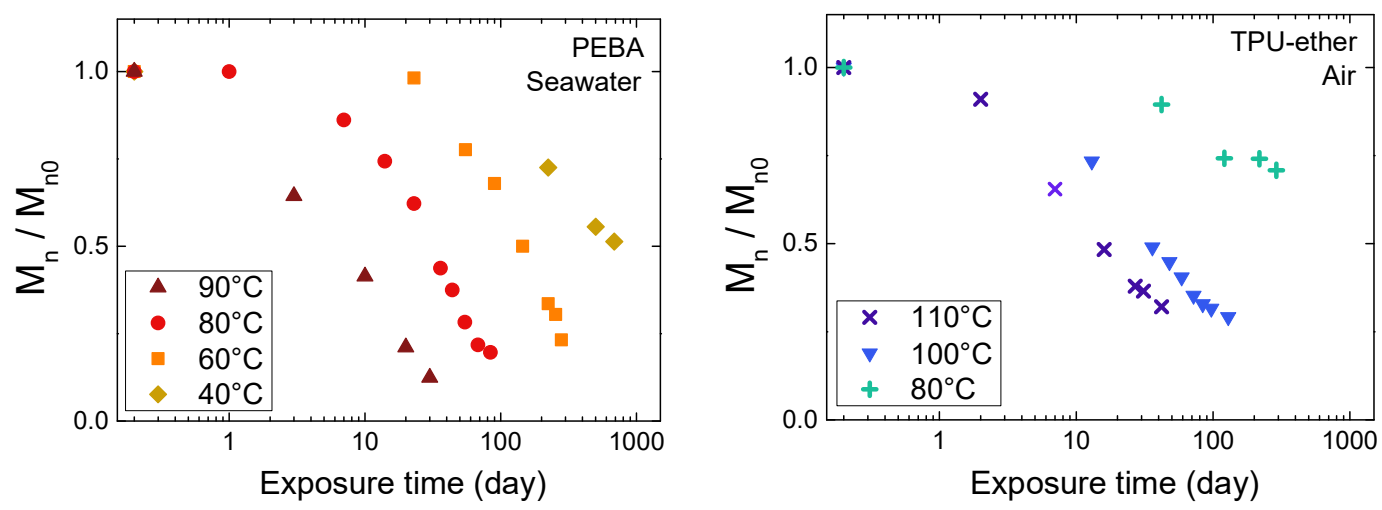

FIGURE 4 Effect of temperature on molar mass decrease for different TPEs in different exposure conditions.

\subsection{Morphology changes}

Segmental urethane and amide copolymers properties strongly depend on their morphology. Hydrogen bonding and hard-soft phase separation determine the morphology of these TPEs. SAXS and WAXS analyses were performed to assess morphology changes during ageing. PEBA aged immerged in seawater at $80^{\circ} \mathrm{C}$ is arbitrarily taken as example. SAXS diffractograms show an intense peak at $q=0.045 \AA$, associated with a long-distance order of the hard segments in 
the PEBA. The characteristic length calculated from the position of this peak shows no significant change up to 30 days. This period is later on identified as the time required to reach the ductile-brittle transition (see Discussion section). Similar results were highlighted for all grades, in all exposure conditions. WAXS diffractograms, reported in complementary information (Figure S2), show no significant change in the crystalline structure of PEBA during ageing.

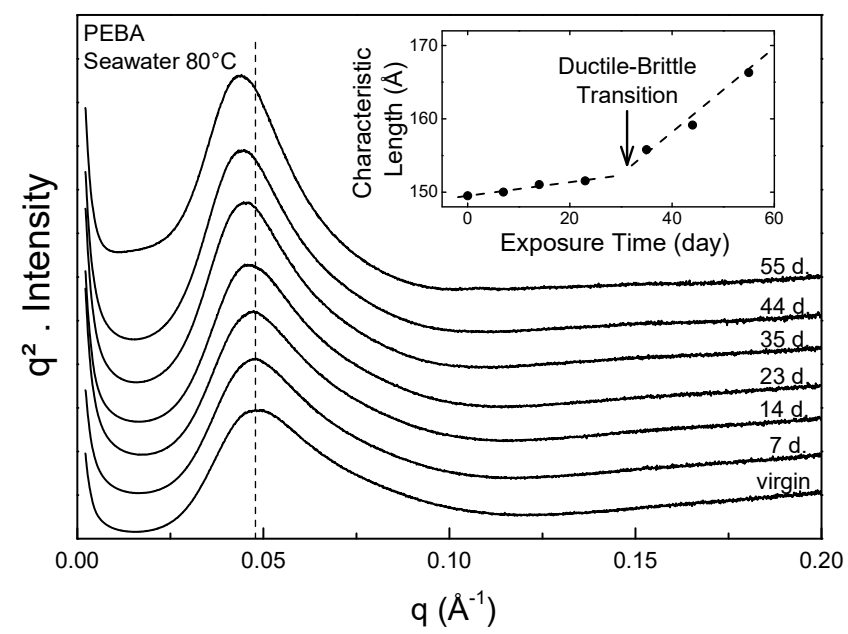

Figure 5 SAXS diffractograms of PEBA aged in seawater at $80^{\circ} \mathrm{C}$. A characteristic length $\mathrm{L}$ associated with the peak at $q=0.045 \AA$ was calculated as $L=\lambda /(2 \sin \theta)$ with $q=4 \pi \cdot \sin (\theta / 2) / \lambda$.

\subsection{Mechanical property changes}

Mechanical properties were characterized by the uniaxial tensile test and the cracking test using the EWF approach. Uniaxial tension is broadly used for polymer characterization, as a quick and simple technique to characterize material mechanical properties. However, the failure properties determined with uniaxial testing are not completely intrinsic to the material, as sample geometry or defects can also interfere. In this respect, the EWF concept involves testing the pre-notched specimen and is thus fully independent of the sample geometry. Since these tests are quite time-consuming, they were only performed on samples aged in specific conditions.

\subsubsection{Uniaxial tension}

Tensile curves are presented as nominal stress $\sigma_{n}=F / S_{0}$ as a function of elongation $\lambda=L / L_{0}$ where $F, S_{0}, L$, and $L_{0}$ are the load, sample initial section, sample length, and initial sample length, respectively. FIGURE 6 shows the change in stress-elongation curve for two cases arbitrarily selected: PEBA immersed in seawater at $80^{\circ} \mathrm{C}$ and TPU-ether exposed to air at $100{ }^{\circ} \mathrm{C}$. At least three samples were tested for each condition. For the purpose of clarity, only one curve per condition is plotted here, considered the most representative of the set. The corresponding molar mass ( $\mathrm{kg} \cdot \mathrm{mol}^{-1}$ ) is indicated next to each curve. We would like to emphasize that although these two specific examples are presented here, all grades in all exposure conditions exhibit the same trend. 

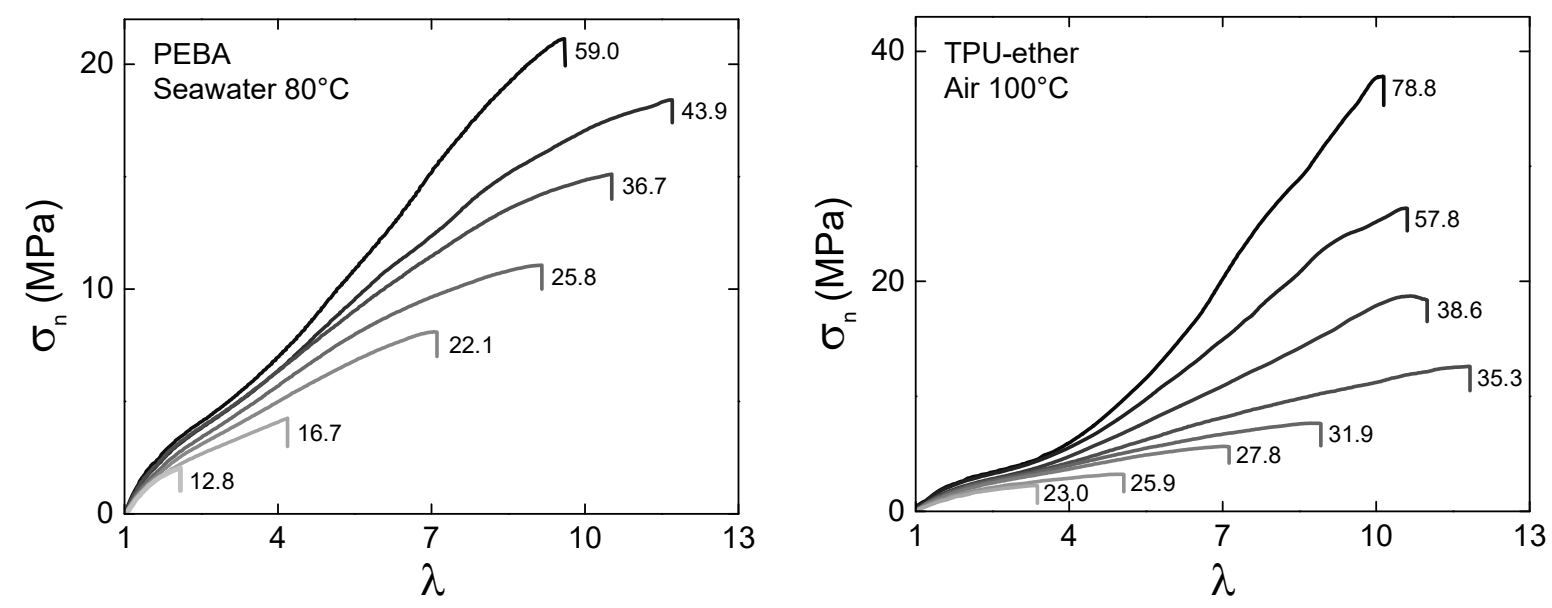

FIGURE 6 Uniaxial tension behavior change of PEBA and TPU-ether in different exposure conditions. Corresponding molar mass $\mathrm{Mn}$ (kg.mol-1) is reported next to each curve.

Typical rubbery behavior is observed, with non-linearity at low elongation, low elastic modulus ( $\mathrm{E} \approx 10 \mathrm{MPa}$ ), and high deformability. A two-step process can globally describe the tensile curve change. First, for low degradation rates (i.e., $\left.M_{n}>35 \mathrm{~kg} \cdot \mathrm{mol}^{-1}\right)$, stress at break $\left(\sigma_{b}\right)$ decreases while elongation at break $\left(\lambda_{b}\right)$ remains rather constant, even showing a small increase in some cases. Second, both $\sigma_{b}$ and $\lambda_{b}$ decrease until reaching a total loss of properties once $\mathrm{M}_{\mathrm{n}}$ drops below $35 \mathrm{~kg} \cdot \mathrm{mol}^{-1}$. It is not completely surprising to observe common behavior, as the same structural degradation phenomenon by scission was identified in all cases in the previous section. It is nevertheless interesting to note that scissions induced by hydrolysis or oxidation seem to have a similar effect on mechanical properties. Even when considering a certain type of exposure alone, cleavage sites are not identical across the different segmented copolymers; we could therefore expect an influence of the scission site. For example, considering hydrolysis, we showed that the cleavage occurs within the soft block for TPU-ester, whereas it occurs between hard and soft blocks for PEBA. Therefore, scissions take place in the soft phase for TPU-ester and mainly in the hard/soft interphase for PEBA. Even though the scission site is significantly different between both materials, it seems to have the same effect on tensile properties from a qualitative perspective.

Elongation at break is commonly considered when assessing polymer embrittlement. ${ }^{38}$ $\lambda_{b}$ change during the ageing of two TPEs exposed to seawater or air is reported in Figure 6 (same grade and exposure nature as in Figure 5) but also for all exposure temperatures.
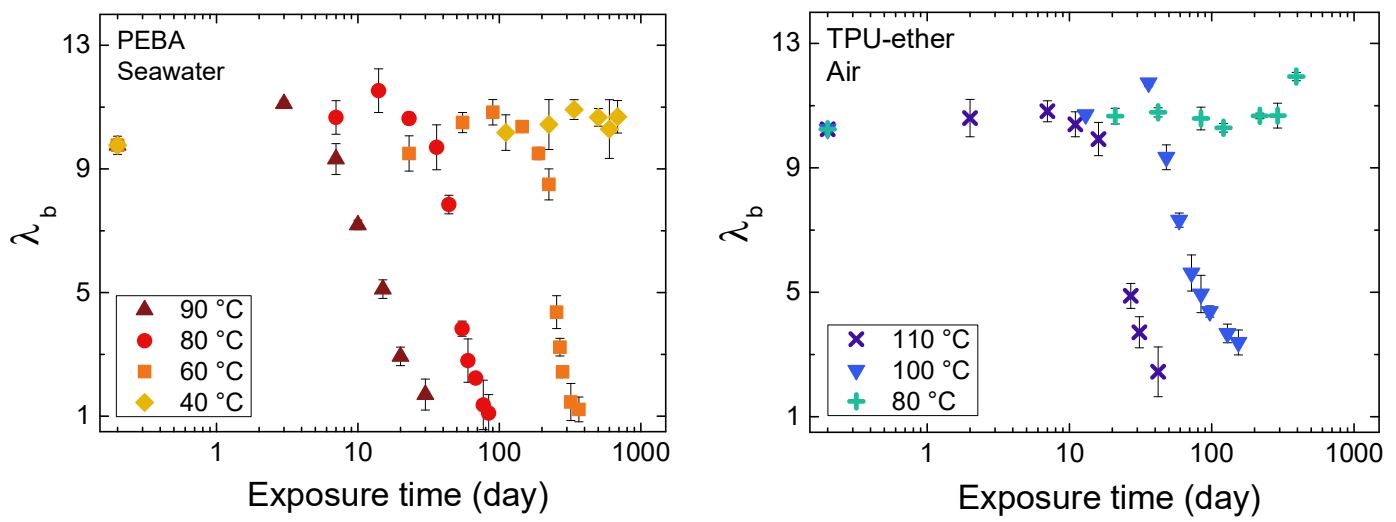
FIGURE 7 Effect of temperature on the kinetics of elongation at break decrease for PEBA and TPU-ether in different exposure conditions.

The same trend, a plateau followed by a drop, is clearly observed, regardless of the exposure temperature. This behavior is similar to the embrittlement trend identified in conventional linear polymers. This point will be further discussed in the Discussion section. In the same way as molar mass, $\lambda_{b}$ change is temperature-accelerated for all grades and for both seawater and air exposure. Regarding stress at break, it shows a regular decrease with ageing time (not shown here). This trend is also exhibited in all conditions and is highly affected by exposure temperature. In the complementary information, we report all data relating to elongation and stress at break for all TPEs in all conditions (Figure S1).

\subsubsection{Essential work of fracture}

Tensile testing of dogbone samples was used as a straightforward technique to test the large number of samples considered in this study. Nevertheless, the EWF concept was used to assess the intrinsic mechanical properties more accurately. This concept is relevant when characterizing the failure of ductile materials. It has been applied to many conventional linear polymers. ${ }^{17}$ The concept relies on the introduction of a known defect (i.e., notch) from which the crack propagates in order to determine the intrinsic properties independently from the sample geometry. Few studies in the literature examine polymer ageing using the EWF method, ${ }^{39,40}$ in particular for TPEs. Since this method is rather time-consuming, partly due to the numerous samples required for a given exposure condition, we only focused on one ageing condition: seawater at $80^{\circ} \mathrm{C}$. Therefore, only PEBA and TPU-ester were studied using this method.

As required by the concept, a linear correlation is highlighted between $w_{f}$ and I (FIGURE 8), while considering the plane stress state. Two parameters are determined from this relationship:

- $\quad w_{e}$, essential work of fracture, corresponding to $w_{f}$ extrapolated to $I=0$;

- $\quad \beta w_{p}$, corresponding to the slope of linear regression, with $\beta$ as a geometrical parameter associated with the plastic deformation area and $w_{p}$ as the non-essential work of fracture.

Immersion in seawater at $80^{\circ} \mathrm{C}$ leads to a flattening of the $w_{f}-1$ curve for both materials, reflected by a regular decrease in $\beta w_{p}$ with molar mass decrease, whereas $w_{e}$ remains roughly constant. 

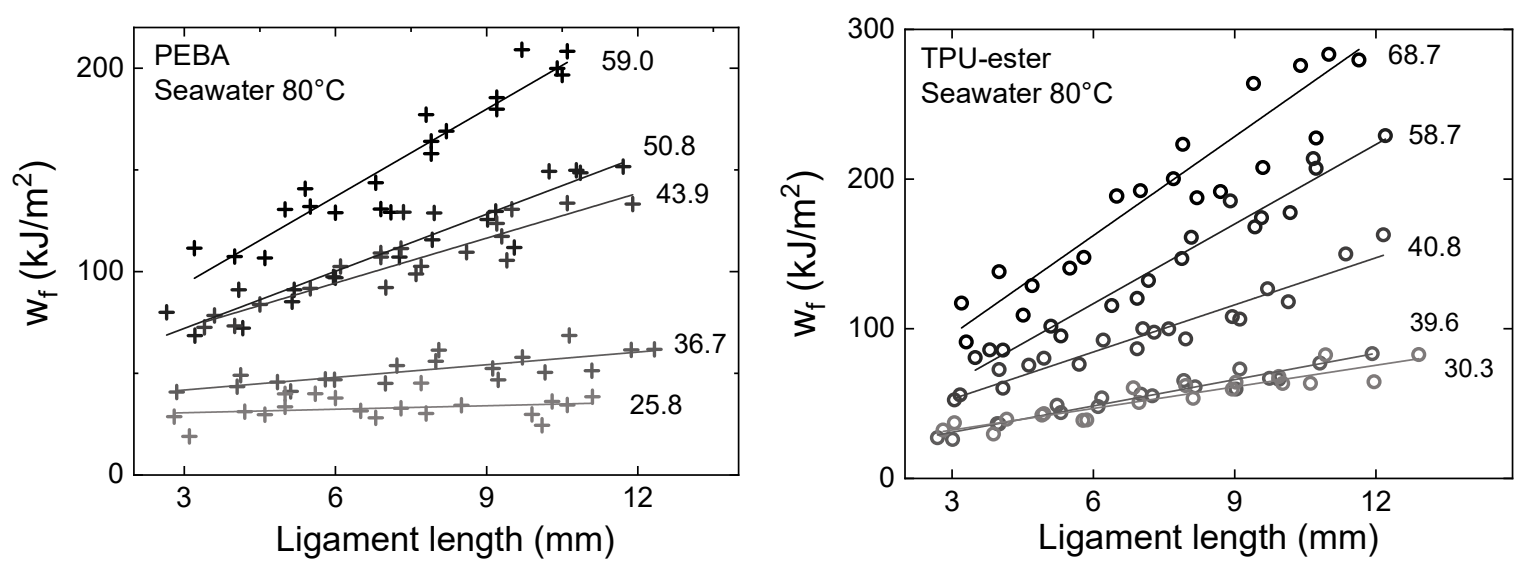

FIGURE 8 Specific essential work of fracture $\left(w_{f}\right)$ as a function of ligament length for PEBA and TPU-ester at different ageing rates (immersion in seawater at $80^{\circ} \mathrm{C}$ ). Corresponding molar mass $\left(\mathrm{kg}^{\mathrm{mol}}{ }^{-1}\right)$ is indicated next to each curve.

Although $\mathrm{w}_{\mathrm{e}}$ is often presented as the relevant parameter when characterizing fracture properties, ${ }^{41}$ it was observed elsewhere that $\beta w_{p}$ could be more appropriate to assess the embrittlement process of polymers. ${ }^{39}$ This also seems to be the case for PEBA and TPU-ester, as $\beta w_{p}$ exhibits a regular decrease, while the $w_{e}$ trend is less obvious. For instance, $\beta w_{p}=0$ was previously taken as a criterion for PP embrittlement. To decorrelate $\beta$ and $w_{p}$ respective contributions, attempts were made to assess $\beta$ through plastic zone size measurements. ${ }^{41}$ Results were not conclusive due to the high standard deviation associated with difficulties in the process zone measurements. Hence, $\beta w_{p}$ is usually considered as such. However, while it has been used to describe the ductile behavior of various polymers, its physical meaning remains unclear. 


\subsection{Mechanical criterion for embrittlement}

Mechanical properties are often used to understand polymer degradation. For elastomers, end-of-life criteria based on elongation at break are commonly considered, such as a $50 \%$ decrease from the initial elongation at break. However, this criterion is mostly based on empirical observations and does not have any physical basis. We may then wonder if another parameter could be more relevant, especially for TPEs. With this in mind, we compared $\beta w_{p}$ with other mechanical properties in FIGURE 9.
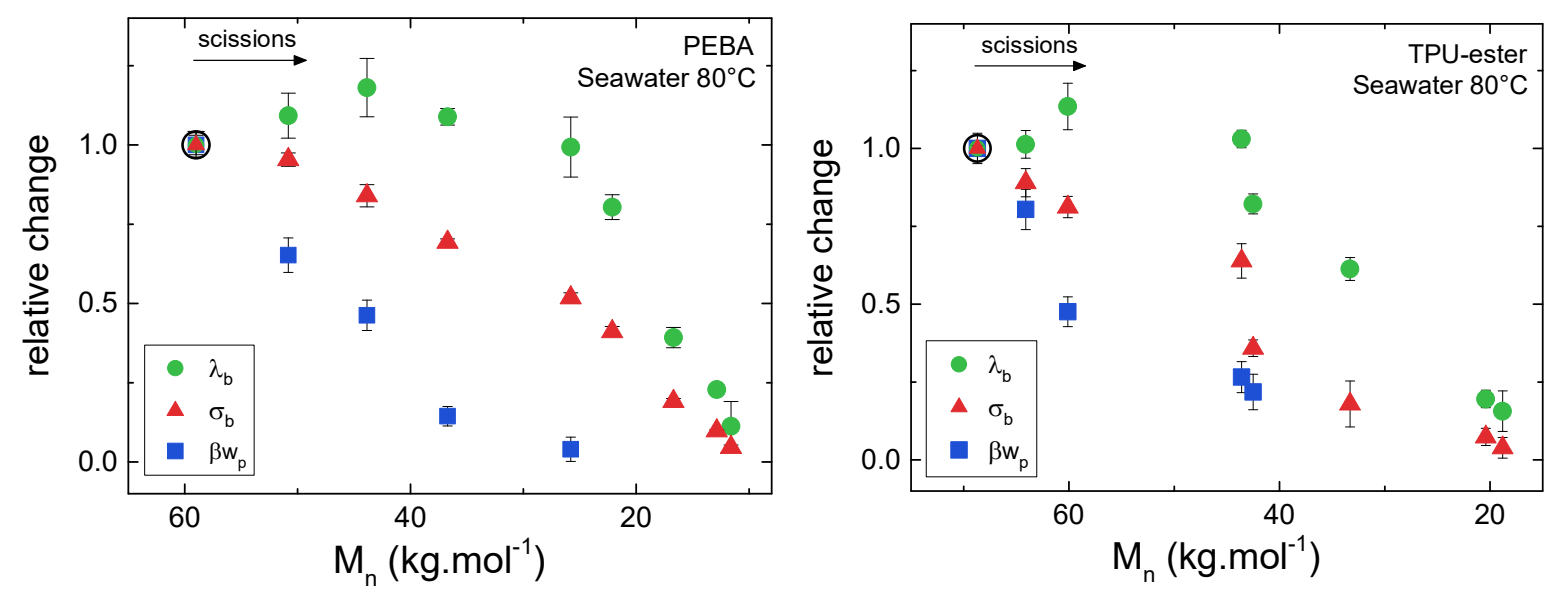

FIGURE 9 Relative change as a function of the molar mass of different tensile properties determined on a dogbone specimen (elongation at break $\lambda_{b}$ and stress at break $\sigma_{b}$ ) and DENT specimen using the EWF method $\left(\beta w_{p}\right)$.

Different tensile properties were considered for this comparison: failure properties $\lambda_{b}$ and $\sigma_{b}$, and $\beta w_{p}$ parameter determined using the EWF concept. Even though it is widely used for thermoset elastomers, elongation at break does not appear to be the best parameter to assess PEBA and TPUs ageing, as it changes slower and less steadily than the others. It is interesting to observe that the criterion $\beta w_{p}=0$, commonly used to identify the ductile-brittle transition in conventional linear polymers, corresponds to the onset of the $\lambda_{b}$ decline. $\beta w_{p}$ shows $a$ significantly higher sensitivity to molar mass change than the other mechanical properties, which could be of great interest from a practical point of view. Indeed, a faster property decrease allows for shorter ageing campaigns, which is an attractive prospect given that these can be time-consuming. It could also enable us to perform campaigns at lower temperatures that are closer to real conditions. Even though additional data are required for a reliable study, it is still noteworthy to observe that for both materials, $\beta w_{p}$ decreases in a similar trend. Further experiments at other exposure conditions or using other PEBAs and TPUs are thus required to confirm this trend. Overall, ageing assessments with $\beta w_{p}$ measurements seem to be a promising prospect and deserve more extensive study.

\subsection{Structure-property relationships}

Mechanical behavior change was monitored with tensile failure properties and parameters derived from the EWF method. We highlighted that regardless of the material or ageing condition, a similar trend is systematically observed, although the kinetics is greatly affected. 
We propose investigating the potential correlation between molar mass and failure properties, which is part of our investigation on the relationship between the structure and mechanical properties of segmental urethane and amide copolymers.

In the Results section, we highlighted an exclusive scission mechanism illustrated by a molar mass decrease. SAXS analyses revealed that no significant morphological changes occurred during the first part of ageing. For instance, in the case of PEBA aged in seawater at $80^{\circ} \mathrm{C}$, the characteristic length associated with a hard phase order remains globally constant up to 30 days, while the molar mass and the stress at break drop by $50 \%$ on this period. Similarly, WAXS analyses showed no changes in the crystalline structure. Same observations were made for all grades, in all exposures. We concluded that the hard phase morphology changes cannot explain the mechanical behaviour changes observed. We thus consider that the scissions occurring in the soft phase is the predominant phenomenon.

It is therefore of great interest to study the potential correlation between molar mass and mechanical properties. In this context, ageing is used here as a means to generate different polymer networks through different means (air or seawater exposures) and at different rates (several temperatures). Thus, the highlighting of a global behavior, manifested by a molar mass-mechanical property master curve independent of the ageing condition, will be taken as evidence of a proper structure-property relationship. FIGURE 10 illustrates elongation at break as a function of molar mass for all TPEs in all conditions studied. The normalized elongation was plotted here in order to compare grades with each other. This graph also includes the results obtained for a fourth grade, a TPU-ester containing an anti-hydrolysis agent (TPU + stabilizer) for which data are available elsewhere. ${ }^{26}$ Even though we previously showed that $M_{n}$ and $\lambda_{b}$ change kinetics strongly depend on ageing conditions, a master curve is highlighted. In the TPU-ester case, although the anti-hydrolysis agent delays the molar mass drop, it does not significantly affect the relationship. Overall, the pattern consistency is particularly remarkable given the large scope of materials and conditions under consideration. This provides strong evidence for a global structure-property relationship in segmental urethane and amide copolymers.

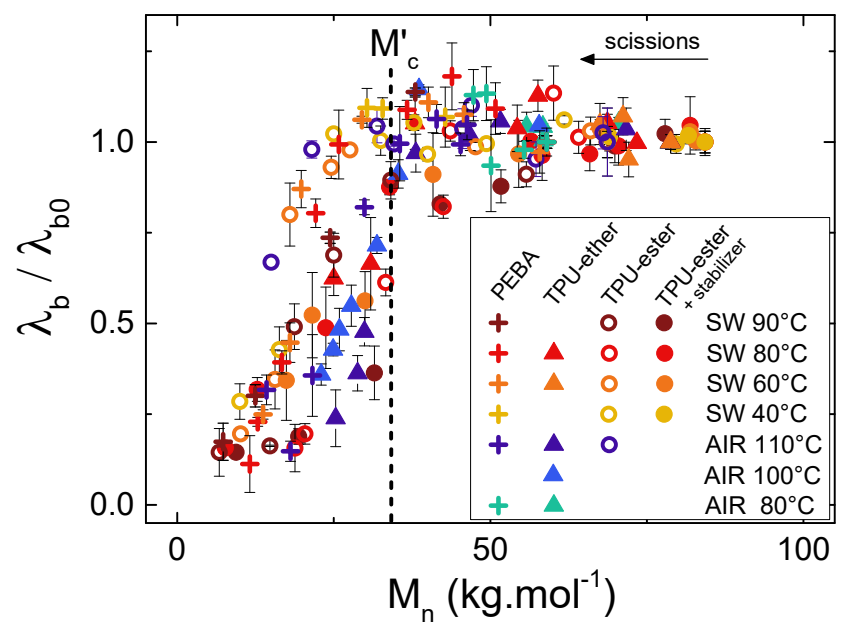

FIGURE 10 Relative elongation at break versus molar mass for all TPEs in all exposure conditions. The stabilized TPU-ester data are taken from a previous study. ${ }^{26}$ 
Elongation at break exhibits a two-step behavior: starting from an unaged sample on the right side of the graph (high molar mass), $\lambda_{b}$ initially exhibits a plateau, with the molar mass decrease having little effect. It then drops once a certain molar mass is reached. Using an elastomer approach, it is generally accepted that elongation at break is linked to the crosslinking density $(\mathrm{v})$, or molar mass between mechanically active crosslinks, according to $\lambda_{b}$ $\propto v^{-1 / 2}$. As the scission process causes $v$ to decrease, we should then observe a $\lambda_{b}$ increase. $A$ slight $\lambda_{b}$ increase observed at low ageing rates (high molar mass) may suggest that TPEs follow this trend to some extent. Nevertheless, this law cannot explain the $\lambda_{b}$ decline.

The $\lambda_{b}$ master curve is very similar to what is observed in conventional linear polymers for which the decrease in fracture properties is associated with a critical molar $\mathrm{M}^{\prime}{ }_{\mathrm{c}}$. Even though the initial molar mass ranges from 41 to $85 \mathrm{~kg} \cdot \mathrm{mol}^{-1}$, the number average molar mass $\left(\mathrm{Mn}_{\mathrm{n}}\right)$ at which $\lambda_{b}$ starts to decrease is estimated at $35 \mathrm{~kg} \cdot \mathrm{mol}^{-1}$ for all grades. This value can also be expressed as a weight average molar mass $\left(\mathrm{M}_{\mathrm{w}}\right)$ of $70 \mathrm{~kg} \cdot \mathrm{mol}^{-1}$, considering that the dispersity remains constant at around 2 (which was indeed observed). Even though it should be carefully considered as it is a standard relative value, it is in the same range of the reported weight average $\mathrm{M}_{\mathrm{c}}$ as thermoplastic polymers that present rubbery amorphous chains such as polyethylene (70 kg. $\left.\mathrm{mol}^{-138}\right)$ and polypropylene $\left(200 \mathrm{~kg} \cdot \mathrm{mol}^{-138}\right)$.

In the literature, $M^{\prime}{ }_{c}$ is linked to the molar mass between entanglements $\left(M_{e}\right)$ as $M^{\prime}{ }_{c}=4-5 M_{e}$ in the case of amorphous linear polymer. A similar trend was observed on several semicrystalline polymers (PP, PE, PTFE, or POM) for which $\mathrm{M}^{\prime}{ }_{\mathrm{c}}=50 \mathrm{Me}$, although the physical meaning of this correlation is less obvious in this case. As these segmental copolymers may crystallize, though generally to a low degree (only a few \%w), we wonder which trend they would follow in this case, perhaps even adopting a new one. Nevertheless, the lack of $M_{e}$ data for TPEs prevents us from drawing any conclusion on this matter. This could be an interesting prospect for future research.

For thermoset elastomers, which are regarded as incompressible materials (Poisson's ratio $=0.5)$, true stress is determined as $\sigma^{\prime}=\sigma_{n} \times \lambda$. This relationship does not apply to PEBA and TPUs, which are not incompressible. Indeed, Poisson's ratio of the TPEs studied here was measured from 0.40 to 0.45 . Nevertheless, we assume that $\sigma_{b} \times \lambda_{b}$ gives a broad approximation of the true stress at break for our copolymers. FIGURE 11 shows the $\sigma_{b} \times \lambda_{b}$ relationship with molar mass. The curves overlap well, with the same slope shared by all grades. A master curve is highlighted here as well. Overall, it is evidenced that the embrittlement process of PEBA and TPUs is closely linked to the molar mass, which has a direct impact on large deformation mechanisms. 


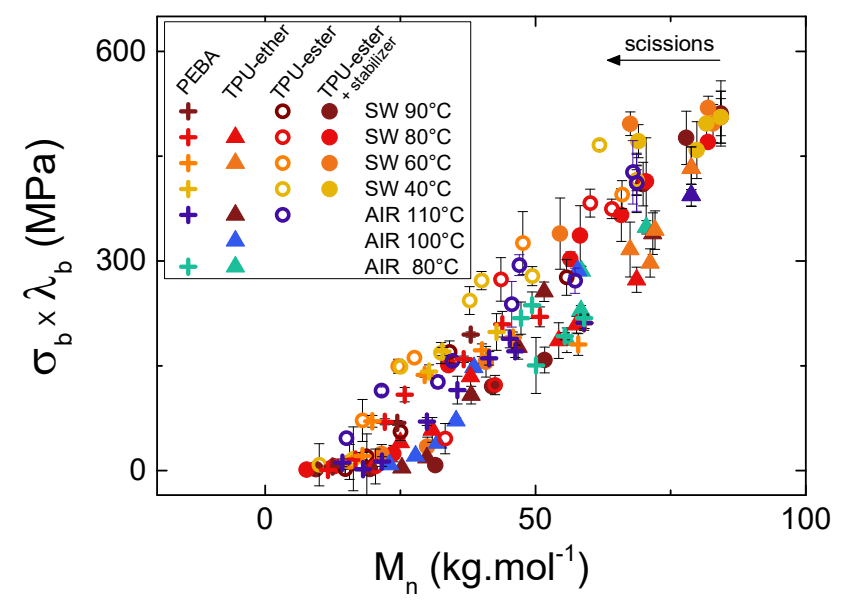

FIGURE 11 True stress $\sigma_{b} \times \lambda_{b}$ versus molar mass for all TPEs in all exposure conditions.

Regarding the origin of this true stress relationship with molar mass, our hypothesis is that it could be linked to strain-induced phenomenon (SIC), which occurs in PEBA and TPUs stretched above a certain elongation. SIC is known to significantly increase the fracture properties, as crystallinity inhibits crack propagation. Thus, the SIC phenomenon is expected to play an important role in terms of failure properties. It could therefore be of interest to investigate SIC mechanisms and the effect of scissions on them in order to elucidate the observed behavior of failure properties. 


\section{CONCLUSION}

To highlight relevant structure-property relationships, three types of segmental urethane and amide copolymers (PEBA, TPU-ester, and TPU-ether), aged in air and seawater at different temperatures, were characterized using GPC, uniaxial tensile testing, and cracking testing. It was shown that all TPEs degrade through an exclusive scission mechanism that results in a molar mass decrease, regardless of the exposure condition. During ageing, elongation at break $\lambda_{b}$ exhibits a plateau followed by a decline, while stress at break $\sigma_{b}$ decreases steadily. $M_{n}, \lambda_{b}$, and $\sigma_{b}$ changes follow the same pattern, regardless of the grade or ageing condition. However, these parameters strongly affect the kinetics. The changes in the intrinsic mechanical properties of PEBA and TPU-ester were assessed with the cracking test on a pre-notched specimen, while considering the EWF concept. The $\beta w_{p}$ parameter seemed particularly appropriate to assess ageing, as it showed a steady and fast decrease.

$\lambda_{b}$ was plotted as a function of $M_{n}$ for each PEBA and TPU, with the master curves highlighting a strong correlation between molar mass and mechanical properties. These relationships appear to be particularly strong considering the range of different exposure conditions (air and seawater at several temperatures), which induce a variety of property kinetics. Furthermore, elongation at break also turned out to be independent of the type. Similar to conventional linear polymers, a critical molar $\mathrm{M}^{\prime}{ }_{c}$ below which failure properties decrease was identified around $35 \mathrm{~kg} \cdot \mathrm{mol}^{-1}$. The $\beta \mathrm{w}_{\mathrm{p}}$ parameter as well as the $\sigma_{b} \times \lambda_{b}$ parameter, which corresponds to the true stress for incompressible material, were also observed to be correlated to molar mass. Overall, a global trend for all the studied TPEs emerges. 


\section{ACKNOWLEDGEMENTS}

We gratefully acknowledge the financial support provided by ANRT (CIFRE N²016/0796). Samples were processed with the kind help of Paulo Ferreira. We also acknowledge the assistance of Sylvie Tencé-Girault, Mickael Premel-Cabic and Nicolas Lacotte, as well as Thomas Bizien and the Synchrotron team. 


\section{REFERENCES}

(1) Buckwalter, D. J.; Dennis, J. M.; Long, T. E. Amide-Containing Segmented Copolymers. Prog. Polym. Sci. 2015, 45, 1-22. https://doi.org/10.1016/j.progpolymsci.2014.11.003.

(2) Yang, I.-K.; Tsai, P.-H. Rheological Characterization and Microphase-Separated Structure of a Poly(Ether-Block-Amide) Segmented Block Copolymer. J. Polym. Sci. Part B Polym. Phys. 2005, 43 (18), 2557-2567. https://doi.org/10.1002/polb.20550.

(3) Paik Sung, C. S.; Schneider, N. S. Structure-Property Relationships of Polyurethanes Based on Toluene Di-Isocyanate. J. Mater. Sci. 1978, $13 \quad$ (8), 1689-1699. https://doi.org/10.1007/BF00548732.

(4) Buckley, C. P.; Prisacariu, C.; Martin, C. Elasticity and Inelasticity of Thermoplastic Polyurethane Elastomers: Sensitivity to Chemical and Physical Structure. Polymer 2010, 51 (14), 3213-3224. https://doi.org/10.1016/j.polymer.2010.04.069.

(5) Prisacariu, C.; Scortanu, E.; Airinei, A.; Agapie, B.; Iurzhenko, M.; Mamunya, Ye. P. New Developments in Thermoplastic Polyurethanes of Variable Crystallinity: Sensitivity of Cyclic Stress-Strain Response to Chemical Structure. Procedia Eng. 2011, 10, 446-454. https://doi.org/10.1016/j.proeng.2011.04.076.

(6) Prisacariu, C.; Scortanu, E.; Agapie, B. Effect of the Hydrogen Bonding on the Inelasticity of Thermoplastic Polyurethane Elastomers. J. Ind. Eng. Chem. 2013, 19 (1), 113-119. https://doi.org/10.1016/j.jiec.2012.07.012.

(7) Sheth, J. P.; Klinedinst, D. B.; Wilkes, G. L.; Yilgor, I.; Yilgor, E. Role of Chain Symmetry and Hydrogen Bonding in Segmented Copolymers with Monodisperse Hard Segments. Polymer 2005, 46 (18), 7317-7322. https://doi.org/10.1016/j.polymer.2005.04.041.

(8) Abouzahr, S.; Wilkes, G. L.; Ophir, Z. Structure-Property Behaviour of Segmented PolyetherMDI-Butanediol Based Urethanes: Effect of Composition Ratio. Polymer 1982, 23 (7), $1077-$ 1086. https://doi.org/10.1016/0032-3861(82)90411-6.

(9) Lorenzo, M. L. D.; Pyda, M.; Wunderlich, B. Calorimetry of Nanophase-Separated Poly(Oligoamide-Alt-Oligoether)s. J. Polym. Sci. Part B Polym. Phys. 2001, 39 (14), 1594 1604. https://doi.org/10.1002/polb.1131.

(10) Sheth, J. P.; Xu, J.; Wilkes, G. L. Solid State Structure-Property Behavior of Semicrystalline Poly(Ether-Block-Amide) PEBAX ${ }^{\circledR}$ Thermoplastic Elastomers. Polymer 2003, 44 (3), 743-756. https://doi.org/10.1016/S0032-3861(02)00798-X.

(11) Ghosh, S.; Khastgir, D.; Bhowmick, A. K. Effect of Block Molecular Weight on the Mechanical and Dynamic Mechanical Properties of Segmented Polyamide. Polymer 1998, 39 (17), 39673975. https://doi.org/10.1016/S0032-3861(98)00030-5.

(12) Zdrahala, R. J.; Gerkin, R. M.; Hager, S. L.; Critchfield, F. E. Polyether-Based Thermoplastic Polyurethanes. I. Effect of the Hard-Segment Content. J. Appl. Polym. Sci. 1979, 24 (9), 20412050. https://doi.org/10.1002/app.1979.070240912.

(13) White, E. F. T. Polyurethane Handbook Edited by G. Oertel, Hanser Publishers, Munich, 1985. Pp. 629, Price E104.70. ISBN 3-446-13671-1. Br. Polym. J. 1986, 18 (6), 403-404. https://doi.org/10.1002/pi.4980180626.

(14) Yilgor, I.; Eynur, T.; Bilgin, S.; Yilgor, E.; Wilkes, G. L. Influence of Soft Segment Molecular Weight on the Mechanical Hysteresis and Set Behavior of Silicone-Urea Copolymers with Low Hard Segment Contents. Polymer 2011, 52 (2), 266-274. https://doi.org/10.1016/j.polymer.2010.11.040.

(15) Piril Ertem, S.; Yilgor, E.; Kosak, C.; Wilkes, G. L.; Zhang, M.; Yilgor, I. Effect of Soft Segment Molecular Weight on Tensile Properties of Poly(Propylene Oxide) Based Polyurethaneureas. Polymer 2012, 53 (21), 4614-4622. https://doi.org/10.1016/j.polymer.2012.08.020.

(16) Dannoux, A.; Esnouf, S.; Amekraz, B.; Dauvois, V.; Moulin, C. Degradation Mechanism of Poly(Ether-Urethane) Estane ${ }^{\circledR}$ Induced by High-Energy Radiation. II. Oxidation Effects. $J$. Polym. Sci. Part B Polym. Phys. 2008, 46 (9), 861-878. https://doi.org/10.1002/polb.21419.

(17) Fayolle, B.; Audouin, L.; Verdu, J. A Critical Molar Mass Separating the Ductile and Brittle Regimes as Revealed by Thermal Oxidation in Polypropylene. Polymer 2004, 45 (12), 4323 4330. https://doi.org/10.1016/j.polymer.2004.03.069. 
(18) Kuhn, W. Dependence of the Average Transversal on the Longitudinal Dimensions of Statistical Coils Formed by Chain Molecules. J. Polym. Sci. 1946, 1 (5), 380-388. https://doi.org/10.1002/pol.1946.120010505.

(19) De Almeida, A.; Chazeau, L.; Vigier, G.; Marque, G.; Goutille, Y. Ultimate and Toughness Properties of $\gamma$-Irradiated EPDM. Eur. Polym. J. 2017, 97, 178-187. https://doi.org/10.1016/j.eurpolymj.2017.09.025.

(20) Ahagon, A. Extensibility of Black Filled Elastomers. Rubber Chem. Technol. 1986, 59 (2), 187 203. https://doi.org/10.5254/1.3538192.

(21) Grasland, F.; Chazeau, L.; Chenal, J.-M.; Caillard, J.; Schach, R. About the Elongation at Break of Unfilled Natural Rubber Elastomers. Polymer 2019, 169, 195-206. https://doi.org/10.1016/j.polymer.2019.02.032.

(22) Hentschel, T.; Münstedt, H. Kinetics of the Molar Mass Decrease in a Polyurethane Melt: A Rheological Study. Polymer 2001, 42 (7), 3195-3203. https://doi.org/10.1016/S00323861(00)00489-4.

(23) Armstrong, S.; Freeman, B.; Hiltner, A.; Baer, E. Gas Permeability of Melt-Processed Poly(Ether Block Amide) Copolymers and the Effects of Orientation. Polymer 2012, 53 (6), 1383-1392. https://doi.org/10.1016/j.polymer.2012.01.037.

(24) Konyukhova, E. V.; Buzin, A. I.; Godovsky, Yu. K. Melting of Polyether Block Amide (Pebax): The Effect of Stretching. Thermochim. Acta 2002, 391 (1), 271-277. https://doi.org/10.1016/S0040-6031(02)00189-2.

(25) ESIS-TC4 Group. Testing Protocol for Essential Work of Fracture. Eur. Struct. Integr. Soc. 2001.

(26) Bardin, A.; Le Gac, P.-Y.; Cérantola, S.; Simon, G.; Bindi, H.; Fayolle, B. Hydrolytic Kinetic Model Predicting Embrittlement in Thermoplastic Elastomers. Polym. Degrad. Stab. 2020, 171, 109002. https://doi.org/10.1016/j.polymdegradstab.2019.109002.

(27) Le Gac, P. Y.; Le Saux, V.; Paris, M.; Marco, Y. Ageing Mechanism and Mechanical Degradation Behaviour of Polychloroprene Rubber in a Marine Environment: Comparison of Accelerated Ageing and Long Term Exposure. Polym. Degrad. Stab. 2012, 97 (3), 288-296. https://doi.org/10.1016/j.polymdegradstab.2011.12.015.

(28) Reano, A. F.; Guinault, A.; Richaud, E.; Fayolle, B. Polyethylene Loss of Ductility during Oxidation: Effect of Initial Molar Mass Distribution. Polym. Degrad. Stab. 2018, 149, 78-84. https://doi.org/10.1016/j.polymdegradstab.2018.01.021.

(29) Okamba-Diogo, O.; Richaud, E.; Verdu, J.; Fernagut, F.; Guilment, J.; Fayolle, B. Molecular and Macromolecular Structure Changes in Polyamide 11 during Thermal Oxidation - Kinetic $\begin{array}{llllll}\text { Modeling. } & \text { Polym. Degrad. }\end{array}$ https://doi.org/10.1016/j.polymdegradstab.2015.06.005.

(30) Le Gac, P.-Y.; Fayolle, B. Impact of Fillers (Short Glass Fibers and Rubber) on the HydrolysisInduced Embrittlement of Polyamide 6.6. Compos. Part B Eng. 2018, 153, 256-263. https://doi.org/10.1016/j.compositesb.2018.07.028.

(31) Rasselet, D.; Ruellan, A.; Guinault, A.; Miquelard-Garnier, G.; Sollogoub, C.; Fayolle, B. Oxidative Degradation of Polylactide (PLA) and Its Effects on Physical and Mechanical Properties. Eur. Polym. J. 2014, 50, 109-116. https://doi.org/10.1016/j.eurpolymj.2013.10.011.

(32) Chapman, T. M. Models for Polyurethane Hydrolysis under Moderately Acidic Conditions: A Comparative Study of Hydrolysis Rates of Urethanes, Ureas, and Amides. J. Polym. Sci. Part Polym. Chem. 1989, 27 (6), 1993-2005. https://doi.org/10.1002/pola.1989.080270620.

(33) Fambri, L.; Penati, A.; Kolarik, J. Synthesis and Hydrolytic Stability of Model Poly(Ester Urethane Ureas). Angew. Makromol. Chem. 1995, 228 (1), 201-219. https://doi.org/10.1002/apmc.1995.052280116.

(34) Schollenberger, C. S.; Stewart, F. D. Thermoplastic Polyurethane Hydrolysis Stability. J. Elastoplast. 1971, 3 (1), 28-56. https://doi.org/10.1177/009524437100300103.

(35) Gardette, J.-L.; Lemaire, J. Oxydation Photothermique d'élastomères de Polyuréthannes Thermoplastiques, 1. Propriétés Des Hydroperoxydes Formés. Makromol. Chem. 1981, 182 (10), 2723-2736. https://doi.org/10.1002/macp.1981.021821019. 
(36) Hoyle, C. E.; Kim, K.-J.; No, Y. G.; Nelson, G. L. Photolysis of Segmented Polyurethanes. The Role of Hard-Segment Content and Hydrogen Bonding. J. Appl. Polym. Sci. 1987, 34 (2), $763-$ 774. https://doi.org/10.1002/app.1987.070340227.

(37) Schubert, M. A.; Wiggins, M. J.; Schaefer, M. P.; Hiltner, A.; Anderson, J. M. Oxidative Biodegradation Mechanisms of Biaxially Strained Poly(Etherurethane Urea) Elastomers. $J$. Biomed. Mater. Res. 1995, 29 (3), 337-347. https://doi.org/10.1002/jbm.820290309.

(38) Fayolle, B.; Richaud, E.; Colin, X.; Verdu, J. Review: Degradation-Induced Embrittlement in Semi-Crystalline Polymers Having Their Amorphous Phase in Rubbery State. J. Mater. Sci. 2008, 43, 6999-7012. https://doi.org/10.1007/s10853-008-3005-3.

(39) Fayolle, B.; Audouin, L.; Verdu, J. Radiation Induced Embrittlement of PTFE. Polymer 2003, 44 (9), 2773-2780. https://doi.org/10.1016/S0032-3861(03)00116-2.

(40) Benítez, A.; Sánchez, J. J.; Arnal, M. L.; Müller, A. J. Monitoring Abiotic Degradation of Branched Polyethylenes Formulated with Pro-Oxidants through Different Mechanical Tests. Polym. Degrad. Stab. $\quad$ 2013, $98 \quad$ (9), https://doi.org/10.1016/j.polymdegradstab.2013.06.004.

(41) Ferrer-Balas, D.; Maspoch, M. L.; Martinez, A. B.; Ching, E.; Li, R. K. Y.; Mai, Y.-W. Fracture Behaviour of Polypropylene Films at Different Temperatures: Assessment of the EWF Parameters. Polymer 2001, 42 (6), 2665-2674. https://doi.org/10.1016/S0032-3861(00)00603-0. 


\section{GRAPHICAL ABSTRACT}

ANTOINE BARDIN, PIERRE-YVES LE GAC, HERVE BINDI, BRUNO FAYOLLE

RELATIONSHIPS BETWEEN MOLAR MASS AND FRACTURE PROPERTIES OF SEGMENTED URETHANE AND AMIDE COPOLYMERS MODIFIED BY CHEMICAL DEGRADATION

GRAPHICAL ABSTRACT FIGURE
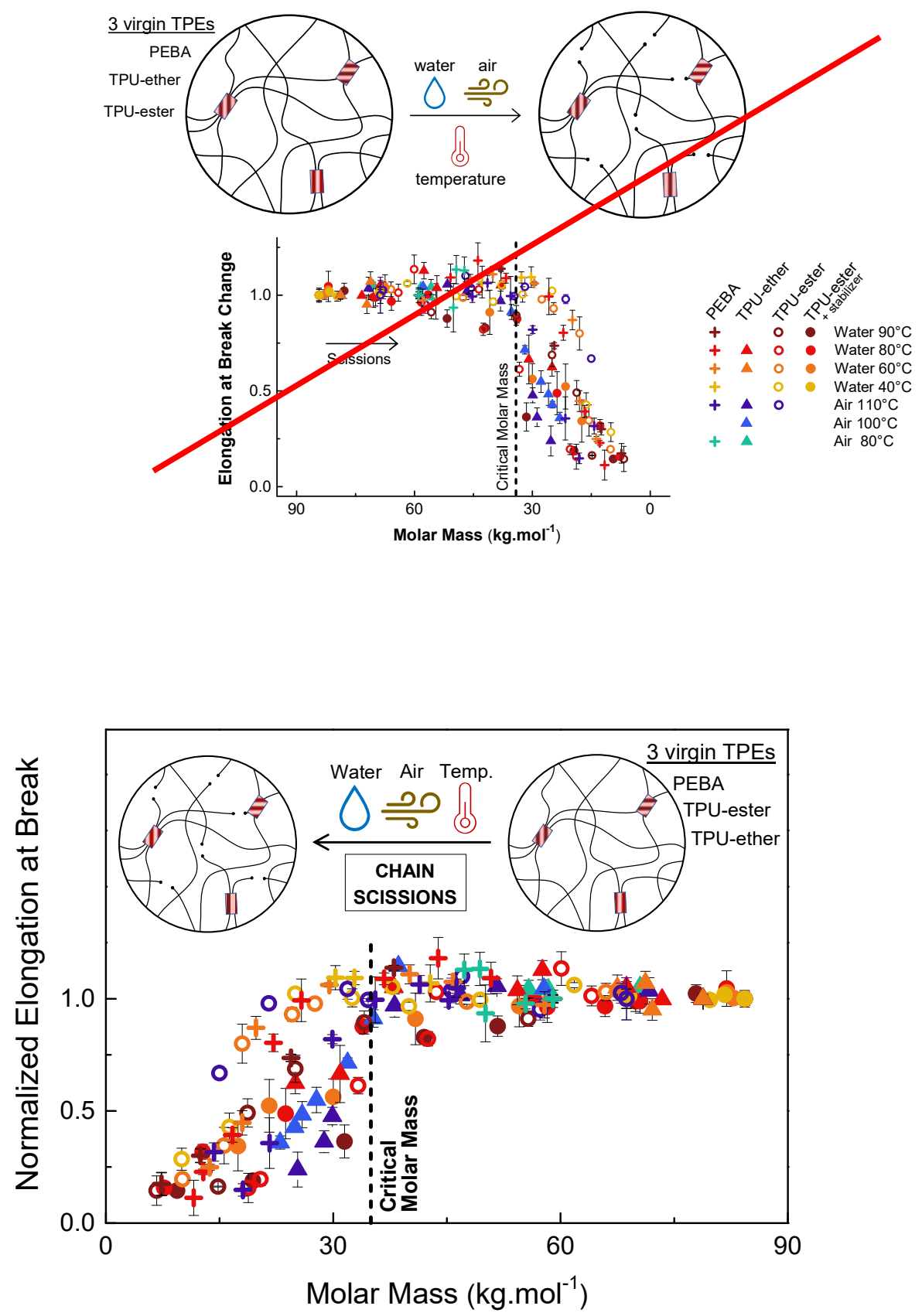

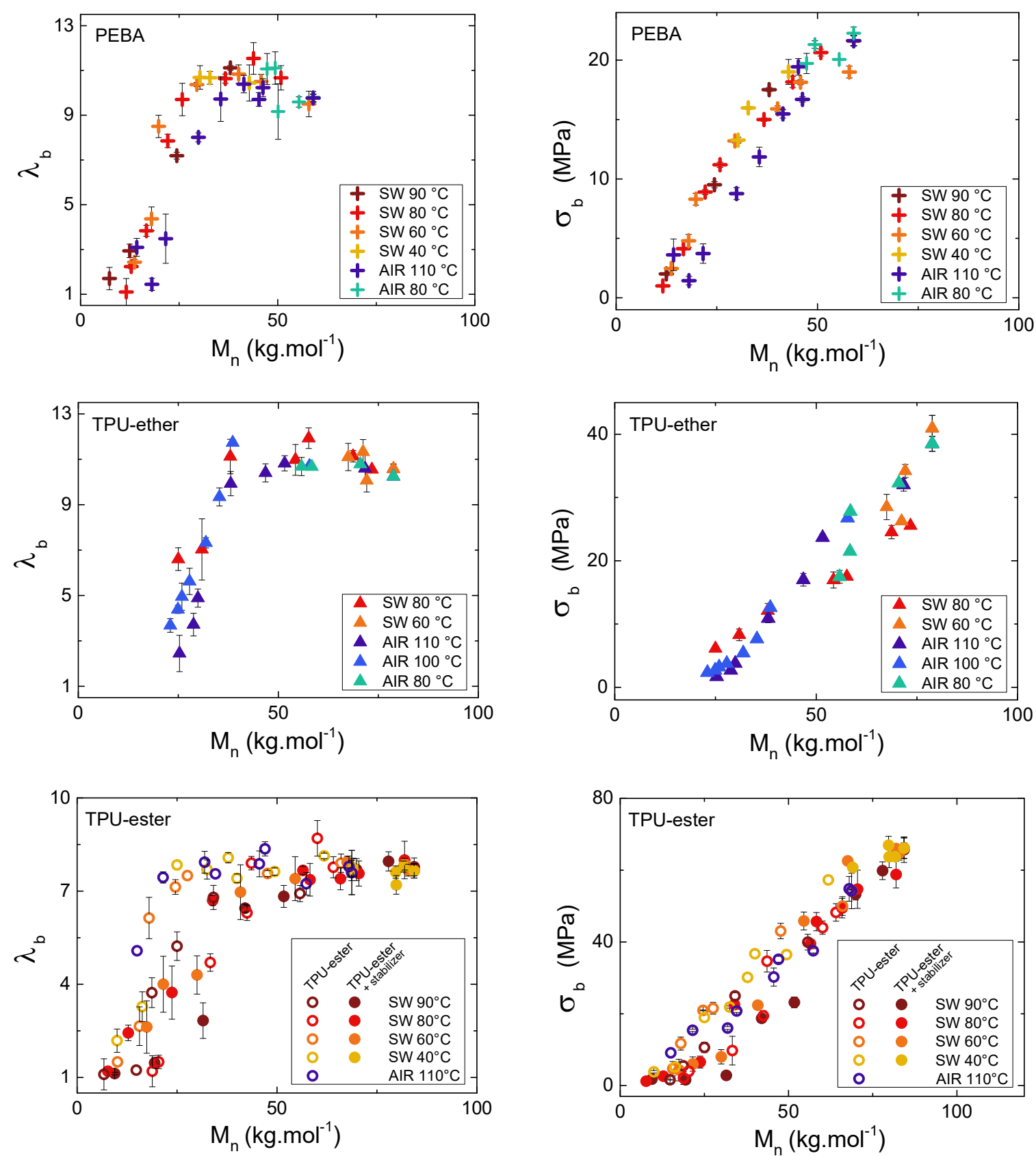

FIGURE S1 Elongation at break (left) and stress at break (right) as a function of molar mass for all TPEs studied in all conditions. TPU-ester data use a raw grade and a second grade containing an anti-hydrolysis agent referred as a stabilizer. 


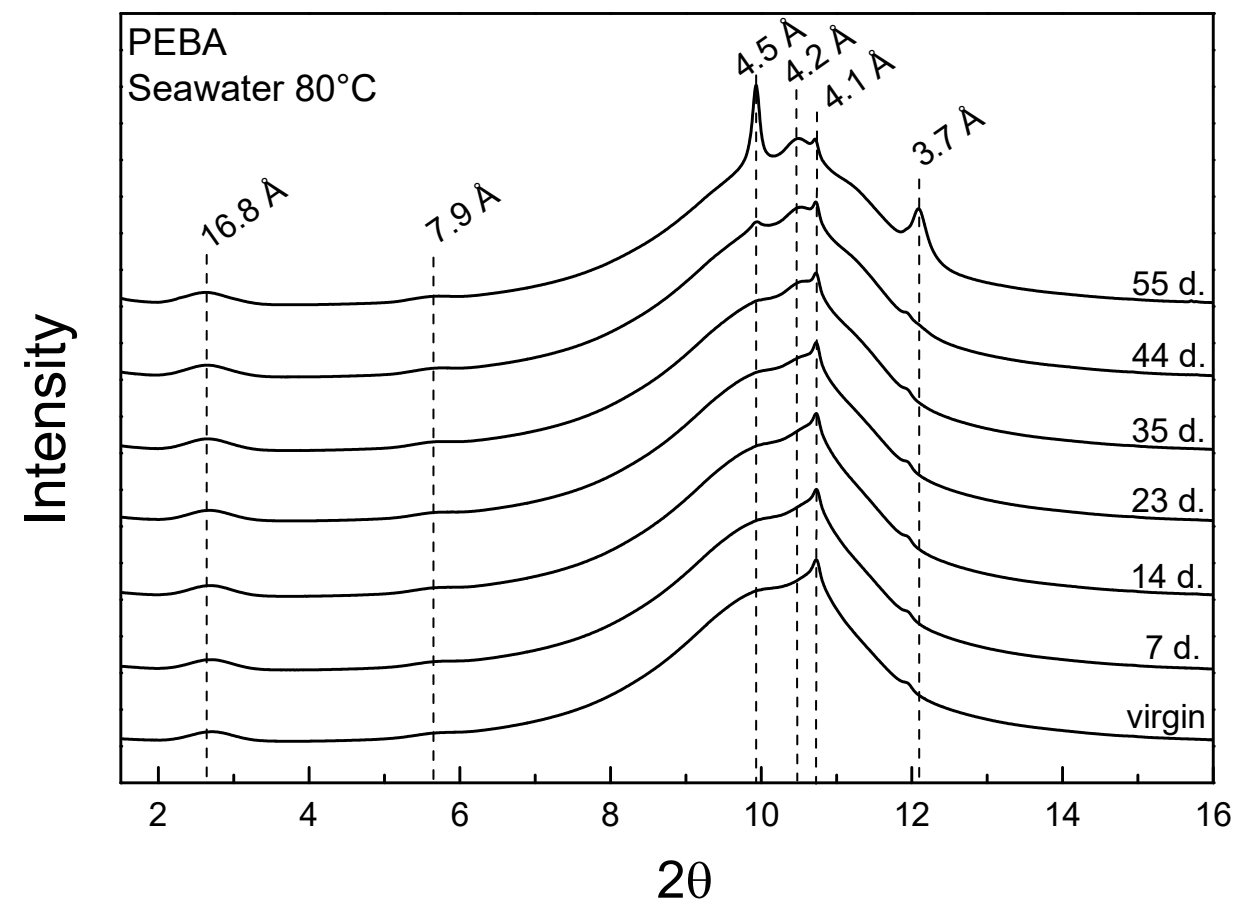

FIGURE S2 WAXS diffractograms of PEBA aged in seawater at $80^{\circ} \mathrm{C}$. 